\title{
Ammonia Adducts of Several Sulfonamides and Their Application to Particle Size Reduction ${ }^{1,2)}$
}

\author{
Keiji Sekiguchi, Motoko Kanke, Yasuyuki Tsuda, and Kenichi Shirotani \\ School of Pharmacentical Sciences, Kitasato University ${ }^{3)}$
}

(Received June 25, 1980)

\begin{abstract}
Adduct formation with $\mathrm{NH}_{3}$ was confirmed with 6 sulfonamides (sulfadimethoxine, sulfamethoxazole, sulfanilamide, sulfaphenazole, sulfisomidine, and sulfisoxazole). The thermal and physico-chemical properties of these adducts were investigated by differential scanning calorimetry, thermogravimetry, X-ray powder diffractometry, infrared spectroscopy, and scanning electron microscopy. It was found that one, two or even three kinds of $\mathrm{NH}_{3}$ adducts were formed by the above sulfonamides. When the specific surface areas of the sulfonamides recovered by desorbing $\mathrm{NH}_{3}$ from the adducts were measured. by a gas adsorption (BET) method, their particle sizes were found to have been effectively reduced. In addition, variations often found in the DSC and TG curves of these adducts are discussed.
\end{abstract}

Keywords_-sulfonamides; ammonia adduct; thermal behavior of ammonia adduct; differential scanning calorimetry; ammonia sorption and desorption; particle size reduction

As described in the previous papers, ${ }^{4)}$ effective particle size reduction has been achieved with several sulfonamides, barbiturates, and chloramphenicol and its palmitate by the formation of $\mathrm{NH}_{3}$ adducts and subsequent elimination of $\mathrm{NH}_{3}$ from these adducts. In the present study, 6 of 8 sulfonamides were confirmed to form $\mathrm{NH}_{3}$ adducts by means of differential scanning calorimetry (DSC), evolved gas detection (EGD), thermogravimetry (TG), X-ray diffractometry, infra-red spectroscopy (IR), and scanning electron microscopy. The specific surface areas of the sulfonamide powders recovered under controlled conditions were measured by a gas adsorption (BET) method.

\section{Experimental}

Materials__-Sulfadimethoxine, sulfamethoxypyridazine, sulfamonomethoxine, sulfanilamide, sulfaphenazole, sulfisomidine, and sulfisoxazole (J.P.VIII grade); sulfamethoxazole (Sinomin ${ }^{\mathbb{B}}$; Shionogi Pharmaceutical Co., Ltd.).

Liquid $\mathrm{NH}_{3}$ in a steel bomb was employed as a source of $\mathrm{NH}_{3}$.

Preparation of $\mathbf{N H}_{3}$ Adducts_- The method of crystallization of $\mathrm{NH}_{3}$ adducts from $\mathrm{NH}_{3}$ solution was the same as described previously. ${ }^{4} a$ )

Simultaneous DSC and EGD Measurements_-Simultaneous DSC and EGD measurements were done with a Perkin-Elmer DSC-1B differential scanning calorimeter. Nitrogen gas was passed through the furnace chamber, and the dissociated $\mathrm{NH}_{3}$ gas from the sample was identified with Nessler's reagent solution as described previously. ${ }^{4} a$ ) A sample amount of $1-13 \mathrm{mg}$ was used after precise weighing with a semi-micro-

1) This paper forms Part XI of "Studies on Methods of Particle Size Reduction of Medicinal Compounds." Part X: K. Sekiguchi, K. Shirotani, H. Yuasa, E. Suzuki, and F. Nakagawa, Chem. Pharm. Bull., 28, 3203 (1980).

2) A part of this work was presented at the 95th Annual Meeting of the Pharmaceutical Society of Japan, Nishinomiya, April 1975; and at the 22nd Annual Meeting of the Kanto Branch. Pharmaceutical Society of Japan, Tokyo, November 1978.

3) Location: 9-1 Shirokane 5-chome, Minato-ku, Tokyo, 108, Japan.

4) a) K. Sekiguchi, Y. Tsuda, and M. Kanke, Chem. Pharm. Bull., 22, 2972 (1974); b) K. Sekiguchi, Y. Tsuda, M. Kanke, E. Suzuki, and M. Iwatsuru, ibid., 26, $1279(1978)$; c) Y. Tsuda, M. Kanke, I. Miyachi, K. Maeno, and K. Sekiguchi, ibid., 28, 947 (1980). 
balance.

TG-A Perkin-Elmer TGS-1 thermobalance was used. The sample weight was 1.8 - 7.6 mg, the sample container was an uncovered platinum pan, and a heating rate of $8^{\circ}$ and $16^{\circ} / \mathrm{min}$ was adopted.

Measurement of Weight Decrease-A chemical balance (type 2452, Sartorius) was used to obtain the weight decrease curve for an $\mathrm{NH}_{3}$ adduct of sulfanilamide at $24.0 \pm 0.3^{\circ}$.

X-ray Powder Diffractometry-The instrument used was a JEOL JDX-7F X-ray diffraction analyzer $(\mathrm{Cu}-\mathrm{K} \alpha$ ray, $\lambda=1.542 \AA ; \mathrm{Ni}$ filter $)$.

IR_-A Jasco IRA-1 grating infrared spectrophotometer was used.

Scanning Electron Microscopy-External appearances of the adduct crystals and of their dissociated forms were observed with a scanning electron microscope (Hitachi-Akashi model MSM-4).

Measurement of Specific Surface Area_-A BET gas adsorption apparatus (model P-600, Shibata Chemical Apparatus Mfg. Co., Ltd.) was used. A sample weight of $1-2 \mathrm{~g}$ was taken with $\mathrm{N}_{2}$ gas as the adsorbate.

\section{Results and Discussion}

Six of eight sulfonamides investigated were found to form one, two or even three kinds of $\mathrm{NH}_{3}$ adducts. However, the other two, sulfamethoxypyridazine and sulfamonomethoxine probably formed $\mathrm{NH}_{3}$ adducts, but they could not be obtained as crystals; therefore, these sulfonamides were omitted from the present study.

\section{Thermal Behavior of $\mathrm{NH}_{3}$ Adducts of Sulfonamides}

1. $\mathbf{N H}_{3}$ Adducts of Sulfadimethoxine-Two different kinds of adducts were separated in crystalline states from $\mathrm{NH}_{3}$ solutions of sulfadimethoxine. One of them was isolated only occasionally, but the other was formed easily. A third adduct was also obtained by allowing these crystals to stand at room temperature for a few days. From the total weight decreases in the TG curves in Fig. 1, their molecular ratios were determined to be 1:3,1:2, and 1:1 (sulfadimethoxine: $\mathrm{NH}_{3}=1: 3.02,1: 1.96$, and $1: 1.02$ ), respectively.

The thermal behavior of the $1: 2$ and $1: 3$ adducts was more complicated than that of the $1: 1$ adduct and was influenced markedly by the measurement conditions. In the case of the $1: 2$ adduct, which was separated frequently from $\mathrm{NH}_{3}$ solution, two sets of representative thermograms were obtained by simultaneous DSC and EGD under semi-closed conditions and by TG, as depicted in Fig. 1 (b)-(d) and (e)-(g). With finer particles at a heating rate below $16^{\circ} / \mathrm{min}$, the DSC curve (b) showed no fluctuation and both the number and the positions of the peaks were almost constant except that the sharp endotherm at about $170^{\circ}$ was often divided into two peaks. The corresponding TG curve (d) gave a parallel step at just half the total weight decrease of the $1: 2$ adduct. Thus, one mole of $\mathrm{NH}_{3}$ was released corresponding to the broad DSC peak $\left(70-130^{\circ}\right)$ and one mole corresponding to the sharp endotherm $\left(170^{\circ}\right)$ on heating. Since the last DSC peak coincides with the melting peak of sulfadimethoxine and the second EGD peak appears below the temperature of this last DSC peak, it is clear that complete elimination of $\mathrm{NH}_{3}$ from the $1: 2$ adduct occurred before melting of the recovered sulfadimethoxine.

On the other hand, when the sample particles were rather coarse and the heating rate was over $16^{\circ} / \mathrm{min}$, quite different DSC, EGD, and TG curves were obtained with the same 1:2 adduct, as depicted in Fig. 1 (e)-(g). Comparing these curves with those obtained with finer particles at slower heating rates, it is clear that the characteristic differences between the two are as follows.

(1) The second endothermic peak in curve (e) showed an irregular shape and, superimposed on this, a sharp exothermic peak that is absent in curve (b).

(2) Although the melting peak of recovered sulfadimethoxine appeared in each DSC curve, the endothermic peak at about $170^{\circ}$ in curve (b), which indicates the presence of the 1: 1 adduct, disappeared completely in curve (e).

(3) As shown in the EGD curves (c) and (f), elimination of $\mathrm{NH}_{3}$ was completed more readily in the case of curve (f).

(4) The second step in the TG curve (g) is not as clear as that in the TG curve (d), and 


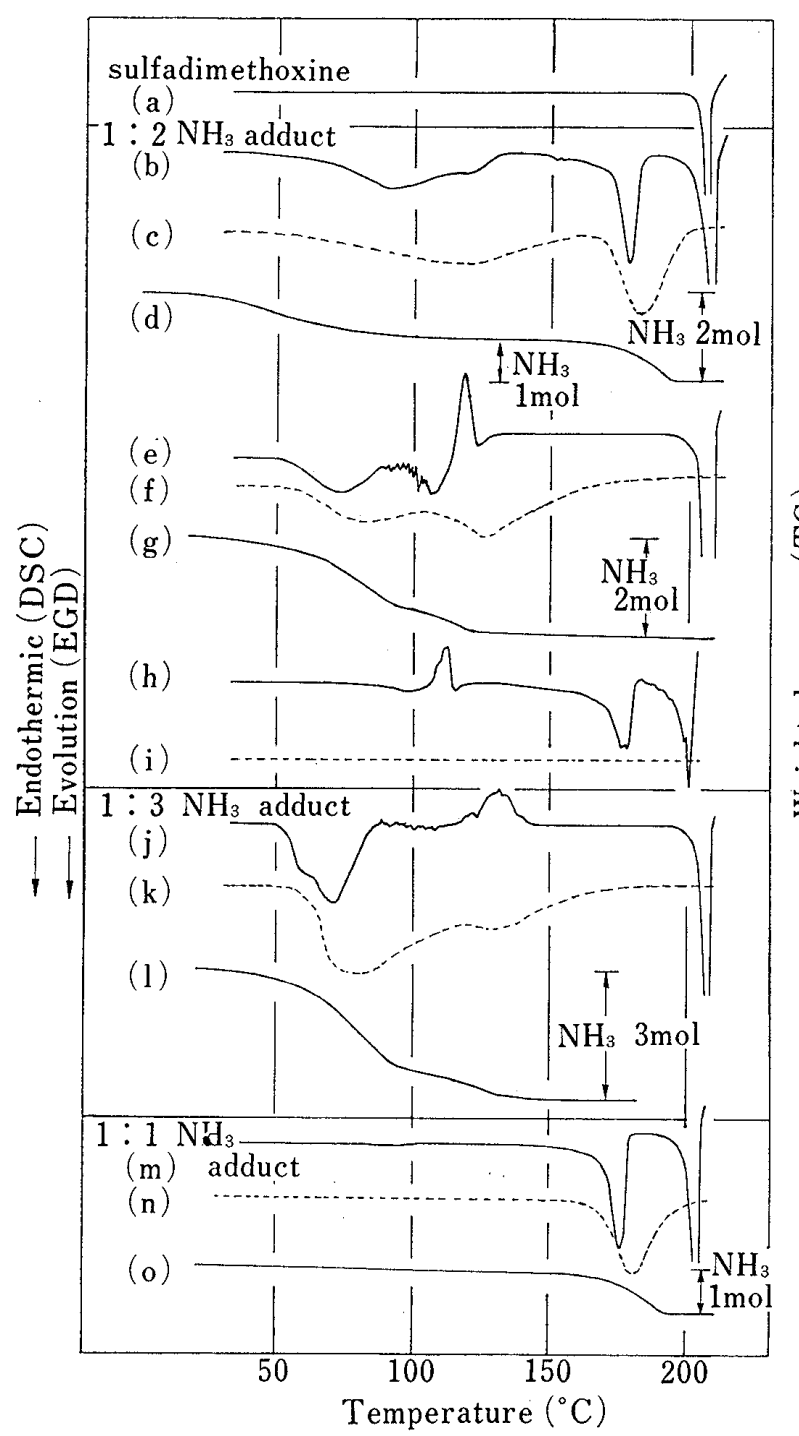

Fig. 1. DSC, EGD, and TG Curves of Sulfadimethoxine and Its $1: 3,1: 2$, and $1: 1 \mathrm{NH}_{3}$ Adducts

(a) DSC curve of sulfadimethoxine under semi-closed conditions: sample weight, $2.06 \mathrm{mg}$; heating rate, $16^{\circ} / \mathrm{min}$.

(b) and (c) Simultaneous DSC and EGD curves of the 1:2 adduct after trituration under semi-closed conditions: sample weight, $11.78 \mathrm{mg}$, heating rate, $16 \% \mathrm{~min}$.

(d) TG curve of the 1:2 adduct corresponding to the DSC curve (b): sample weight, $7.590 \mathrm{mg}$, heating rate, $8^{\circ} / \mathrm{min}$.

(e) and (f) Simultaneous DSC and EGD curves of the 1:2 adduct without trituration under semi-closed conditions: sample weight, $5.01 \mathrm{mg}$; heating rate, $16^{\circ} / \mathrm{min}$.

(g) TG curve of the 1:2 adduct corresponding to the DSC curve (e): sample weight, $3.891 \mathrm{mg}$; heating rate, $16^{\circ} / \mathrm{min}$.

(h) and (i ) Simultaneous DSC and EGD curves of the 1: 2 adduct under closed conditions: sample weight, $0.69 \mathrm{mg}$; heating rate, $16^{\circ} / \mathrm{min}$.

(j) and (k) Simultaneous DSC and EGD curves of the 1:3 adduct under semi-closed conditions: sample weight, $4.09 \mathrm{mg}$; heating rate, $16^{\circ} / \mathrm{min}$.

(1) TG curve of the 1: 3 adduct: sample weight, $1.753 \mathrm{mg}$; heating rate, $16^{\circ} / \mathrm{min}$.

(m) and (n) Simultaneous DSC and EGD curves of the $1: 1$ adduct under semi-closed conditions: sample weight, $9.60 \mathrm{mg}$; heating rate, $8^{\circ} / \mathrm{min}$.

(o) TG curve of the 1: 1 adduct: sample weight, $6.176 \mathrm{mg}$; heating rate, $16^{\circ} / \mathrm{min}$.

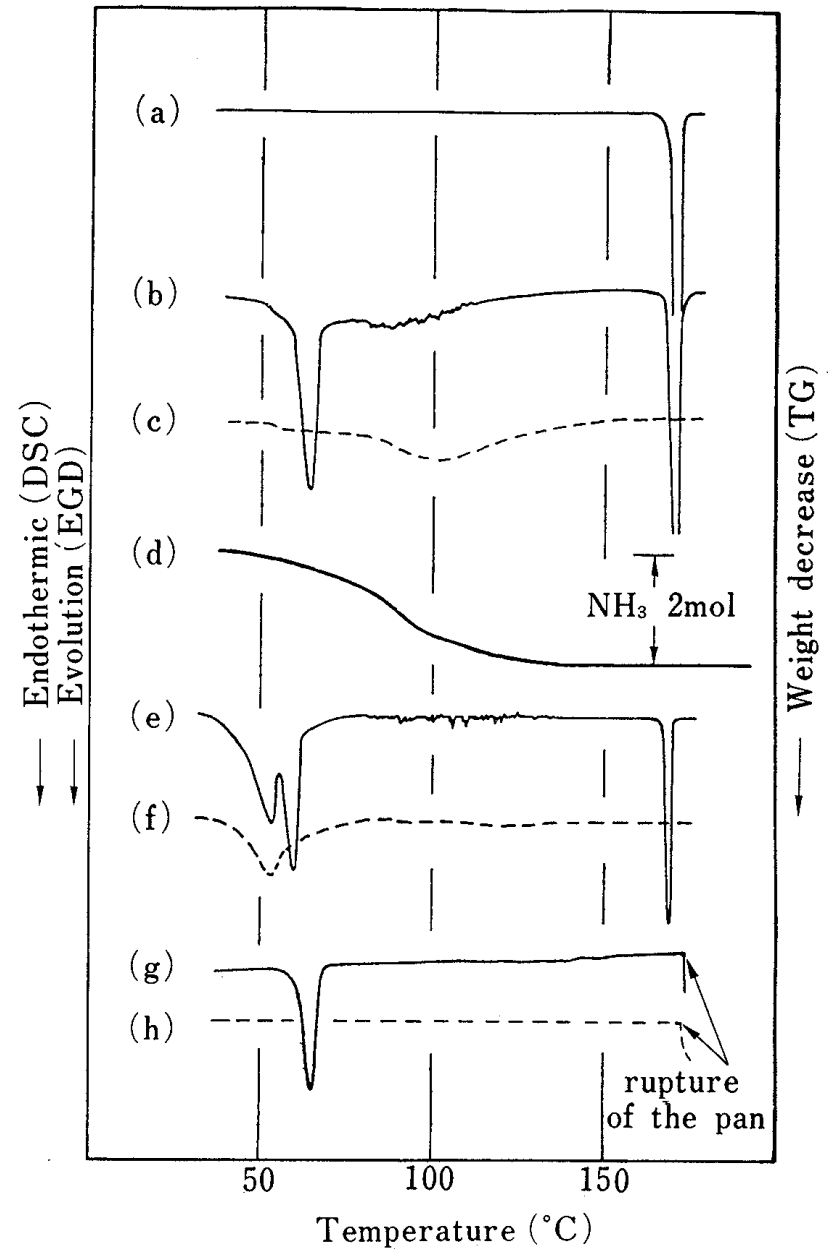

Fig. 2. DSC, EGD, and TG Curves of Sulfamethoxazole and Its $1: 2 \mathrm{NH}_{3}$ Adduct

(a) DSC curve of sulfamethoxazole under semi-closed conditions: sample weight, $10.44 \mathrm{mg}$; heating rate, $8^{\circ} \% \mathrm{~min}$.

(b) and (c) Simultaneous DSC and EGD curves of the 1:2 $\mathrm{NH}_{3}$ adduct under semi-closed conditions: sample weight, $3.32 \mathrm{mg}$; heating rate, $16^{\circ} / \mathrm{min}$.

(d) TG curve of the $1: 2$ adduct: sample weight, $2.719 \mathrm{mg}$; heating rate, $16^{\circ} / \mathrm{min}$.

(e) and (f) Simultaneous DSC and EGD curves of the 1:2 adduct under semi-closed conditions: sample weight, 12.40 ing; heating rate, $2^{\circ} / \mathrm{min}$.

(g) and (h) Simultaneous DSC and EGD curves of the 1: 2 adduct under closed conditions: sample weight, $1.95 \mathrm{mg}$; heating rate, $16 \% \mathrm{~min}$. 
appeared at much lower temperature. Further, the decrease in weight was not stoichiometric and varied considerably.

Judging from these results, we consider that a metastable conversion from the $1: 2$ adduct to free sulfadimethoxine occurred at faster heating rates with coarse sample crystals due to a retardation of deammoniation.

Since under closed conditions of DSC measurement, no $\mathrm{NH}_{3}$ gas evolves until the sample pan is ruptured by the gas pressure, the change in composition of the condensed phase of the sample should be less than that under semi-closed conditions. Therefore, the above assignments of the DSC curves would be more reliable if simultaneous DSC and EGD of the 1:2 adduct were carried out under closed conditions using a liquid sample pan. However, in contrast to the cases under semi-closed conditions, only one thermogram pattern corresponding to step-wise transition was obtained, as depicted in Fig. 1 (h) and (i). The two exothermic DSC peaks which appeared in the midst of the first and immediately after the second endothermic ones are ascribed to solidification of the $1: 1$ adduct and $\mathrm{NH}_{3}$-free sulfadimethoxine, respectively. The fact that the last peak appeared at a temperature significantly lower than the melting point of sulfadimethoxine can be explained by melting point depression due to the presence of $\mathrm{NH}_{3}$.

In the case of the 1:3 adduct, fewer measurements were done because of the limited amount of samples, and the results obtained were the least reproducible among the three adducts. Considerable change was observed in each run in the range between the first peak and the melting peak of sulfadimethoxine. For this reason, the curves in Fig. 1 (j), (k), and (l) were arbitrarily selected. The first endothermic peak in the DSC curve (j) always appeared at a temperature several degrees lower than those of the $1: 2$ adduct. In addition to the variability of peak appearance, small fluctuations of the curve were observed up to about $150^{\circ}$. Correspondingly, the TG curve showed a gradual but nonstoichiometric step in the same temperature range. Although it was not shown in the figure, the only one DSC curve which suggested the formation of the $1: 1$ adduct by the appearance of the endothermic peak at about $170^{\circ}$ was obtained. These results suggest that formation of the intermediate $1: 2$ and 1:1 adducts from the 1:3 adduct under the conditions adopted was hindered partly or almost completely.

When simultaneous DSC and EGD and the TG were carried out with the $1: 1$ adduct prepared by desorbing $\mathrm{NH}_{3}$ at room temperature, the thermograms obtained were almost the same as those depicted in Fig. 1 (m), (n), and (o) even under different measurement conditions including the heating rate and fineness of the sample particles. The DSC and EGD peaks and the TG step between $170^{\circ}$ and $185^{\circ}$ are definitely attributable to the change from the $1: 1$ adduct to $\mathrm{NH}_{3}$-free sulfadimethoxine. Also, the fact that the thermograms were reproducible indicates that a metastable phase reaction, which occurred with the $1: 2$ and 1: 3 adducts, was not likely in this case.

2. $\mathbf{N H}_{3}$ Adduct of Sulfamethoxazole - The thermograms of free sulfamethoxazole and its $\mathrm{NH}_{3}$ adduct crystallized from an $\mathrm{NH}_{3}$ solution are depicted in Fig. 2. From the total weight change in the TG curve (d), the combining ratio was determined to be $1: 2$ (sulfamethoxazole: $\mathrm{NH}_{3}=1: 2.02$ ).

When simultaneous DSC and EGD measurements were done under closed conditions, the adduct exhibited one sharp endothermic peak at $65^{\circ}$ but none at the melting point of free sulfamethoxazole (Fig. 2 (g) and (h)). In other words, the $\mathrm{NH}_{3}$ adduct itself melted completely and remained in a liquid state until the sample pan ruptured. Further, the broad but very small endothermic heat effect between about $100^{\circ}$ and $160^{\circ}$ is ascribable to partial evaporation of $\mathrm{NH}_{3}$ from the melt into the free space of the sample container.

On the other hand, the simultaneous DSC and EGD curves under semi-closed conditions showed considerably different patterns depending upon the heating rate. At a heating rate of $16^{\circ} / \mathrm{min}$, as shown in curve (b), a sharp endothermic peak with an indistinct shoulder ap- 
peared at almost the same temperature as the melting peak of the $\mathrm{NH}_{3}$ adduct under closed conditions (Fig. $2(\mathrm{~g})$ ). Then, small irregular heat effects appeared between about $80^{\circ}$ and $120^{\circ}$, followed by a sharp melting peak of recovered sulfamethoxazole. Although a very small evolution of $\mathrm{NH}_{3}$ was detected by the simultaneous EGD (curve (c)), corresponding to the first DSC peak, evolution of $\mathrm{NH}_{3}$ proceeded mainly with the second heat effect of the DSC curve (b). Thus, it is suggested that the $\mathrm{NH}_{3}$ adduct melted once, then the melt released $\mathrm{NH}_{3}$ upon subsequent heating to form $\mathrm{NH}_{3}$-free sulfamethoxazole. The unevenness of the second heat effect can be explained by alternate occurrence of evaporation of $\mathrm{NH}_{3}$ (endothermic) and crystallization of $\mathrm{NH}_{3}$-free sulfamethoxazole (exothermic) from the melt.

As the heating rate was decreased, the simultaneous DSC and EGD curves under semiclosed conditions changed gradually to curves (e) and (f). The shoulder of the first DSC peak in curve (b) became more marked until it was replaced by an independent peak, while the original peak shifted gradually to lower temperatures. Since the composition of the sample changes more under semi-closed conditions as the heating rate decreases, the shoulder or the corresponding peak at about $50^{\circ}$ in the DSC curves (b) or (e), respectively, might be caused by a eutectic reaction between the $1: 2$ adduct and sulfamethoxazole, while the successive peak can be assigned to melting of the adduct in the eutectic liquid. In addition, the slower the heating rate, the smaller the irregular heat effect at about $80-120^{\circ}$.

Summarizing those data, we consider that sulfamethoxazole and $\mathrm{NH}_{3}$ give a phase diagram consisting of a 1:2 compound with a congruent melting point.

3. $\mathbf{N H}_{3}$ Adduct of Sulfanilamide _ An adduct of sulfanilamide was obtained from its $\mathrm{NH}_{3}$ solution as transparent prismatic crystals. Once the crystals were removed from $\mathrm{NH}_{3}$ solution, they began to crack and turned opaque with loss of the combined $\mathrm{NH}_{3}$. Its molecular ratio was determined to be $1: 2$ (sulfanilamide: $\mathrm{NH}_{3}=1: 2.01$ ) from the total weight loss in the isothermal weight decrease curve (Fig. 3) of freshly prepared transparent crystals on a chemical balance at $24.0 \pm 0.3^{\circ}$. It was also observed that no liquid was formed during the change in appearance under atmospheric conditions.

The DSC curves from low temperature under semi-closed and closed conditions exhibited two and three peaks below $60^{\circ}$ and $40^{\circ}$, respectively, due to decomposition of the adduct (Fig.

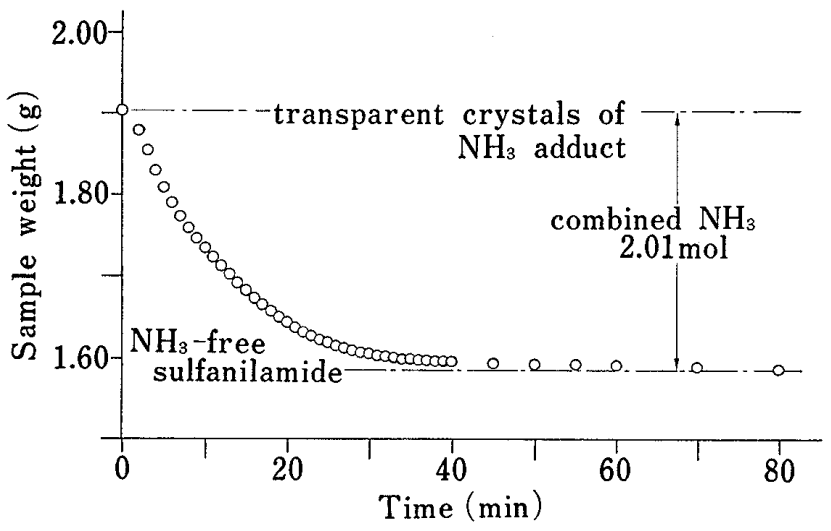

Fig. 3. Weight Decrease Curve of Sulfanilamide $\mathrm{NH}_{3}$ Adduct obtained on a Chemical Balance at $24.0 \pm 0.3^{\circ}$

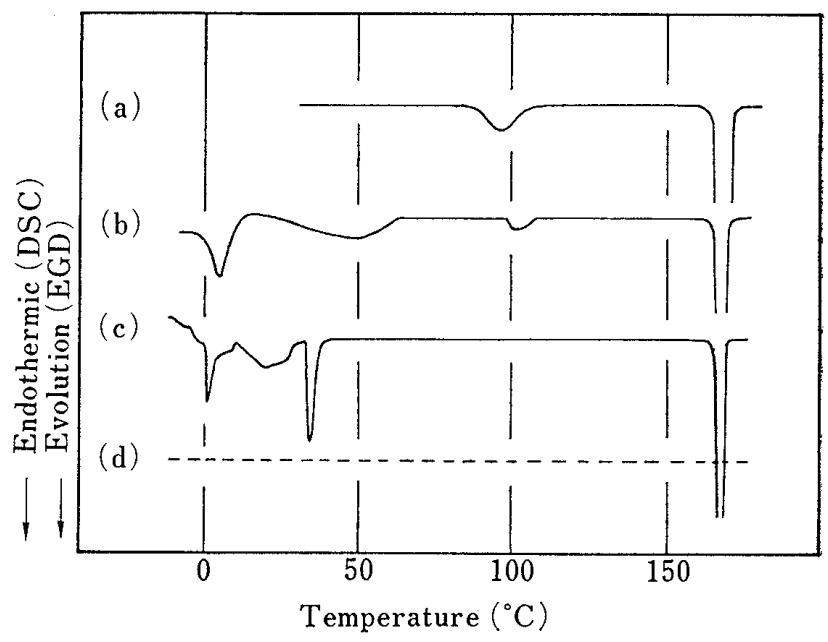

Fig. 4. DSC and EGD Curves of Sulfanilamide and Its $\mathrm{NH}_{3}$ Adduct

(a) DSC curve of the $\alpha$-form of sulfanilamide under semi-closed conditions: sample weight, $7.33 \mathrm{mg}$; heating rate, $16 \% \mathrm{~min}$.

(b) DSC curve of the $\mathrm{NH}_{3}$ adduct under semi-closed conditions: sample weight as sulfanilamide, $7.10 \mathrm{mg}$; heating rate, $8^{\circ} / \mathrm{min}$.

(c) and (d) Simultaneous DSC and EGD curves of the adduct under closed conditions: sample weight, $1.02 \mathrm{mg}$; heating rate, $16 \%$ min. 
4 (b) and (c)). Although a definite assignment was difficult in view of the limited data, liquefaction of the original $\mathrm{NH}_{3}$ adduct and subsequent formation of an intermediate adduct might have occurred during heating under pressurized conditions. The third and the fourth peaks in curve (b) are attributable, from the corresponding X-ray diffraction data, to transition from $\alpha$ - to $\gamma$-forms of sulfanilamide ${ }^{5)}$ and to melting of the latter, respectively.

4. $\mathbf{N H}_{3}$ Adducts of Sulfaphenazole_-An adduct of sulfaphenazole was formed by crystallization from its $\mathrm{NH}_{3}$ solution. An intermediate adduct was also obtained during $\mathrm{NH}_{3}$ elimination by holding the original adduct under reduced pressure at room temperature. From the total weight change in the TG curves in Fig. 5 (d) and (i), their combining ratios were determined to be $1: 2$ and $1: 1$ (sulfaphenazole: $\mathrm{NH}_{3}=1: 1.95$ and $1: 0.99$ ), respectively.

When simultaneous DSC and EGD measurements were done under semi-closed conditions, the 1: 2 adduct exhibited two different patterns. The curves (b) and (c) were obtained in most cases; curves (e) and (f) seldom appeared in the present study. In the former case, the DSC curve (b) showed two distinct endothermic peaks at about $100^{\circ}$ and $185^{\circ}$. In addition, a shallow peak was often observed with a fresh sample at about $60^{\circ}$, which may be due to evaporation of adsorbed $\mathrm{NH}_{3}$. Since the simultaneous EGD curve (c) indicates that $\mathrm{NH}_{3}$ was mainly eliminated in the region of the DSC peak at $100^{\circ}$, it is clear that a direct conversion of the $1: 2$ adduct to free sulfaphenazole occurred in the course of deammoniation. On the other hand, formation of an intermediate 1:1 adduct was confirmed in the latter case by the presence of two separated peaks in curves (e) and (f) below the melting point of the free sulfonamide. However, in spite of repeated trials, all of the TG curves showed a single pattern suggesting direct conversion, as depicted in curve (d).

Simultaneous DSC and EGD curves of the 1:1 adduct under semi-closed conditions are shown in Fig. $5(\mathrm{~g})$ and $(\mathrm{h})$. In contrast to the $1: 2$ adduct, the $1: 1$ adduct exhibited a constant thermogram. The DSC and EGD peaks at about $150^{\circ}$ coincide with the second ones in curves (e) and (f), and are clearly assignable to $\mathrm{NH}_{3}$ elimination.

Overall, it can be said that direct conversion to $\mathrm{NH}_{3}$-free sulfaphenazole occurs easily in practice, although it seems reasonable to expect that the combined $\mathrm{NH}_{3}$ in the $1: 2$ adduct is eliminated step by step.

5. $\mathbf{N H}_{3}$ Adducts of Sulfisomidine —-Two different adducts were separated in crystalline states from $\mathrm{NH}_{3}$ solutions of sulfisomidine. They were both relatively stable and their combining ratios were determined to be $1: 2$ and $1: 3$ (sulfisomidine: $\mathrm{NH}_{3}=1: 1.97$ and 1: 2.99) from the total weight changes in the TG curves in Fig. 6 (h) and Fig. 7 (e).

When simultaneous DSC and EGD measurements were done with the 1:2 adduct under semi-closed conditions, the DSC curve (Fig. 6 (b)) showed two successive endothermic peaks between $90^{\circ}$ and $110^{\circ}$ and a melting peak of the recovered sulfisomidine at about $250^{\circ}$. It is evident from the corresponding EGD curve (c) that the 1:2 adduct liquefies and then releases all of its $\mathrm{NH}_{3}$ at the first two DSC peaks. These DSC peaks were often replaced by a pair of broad endothermic and exothermic ones, as shown in curve (d). Such a change in the DSC curve can be explained by delayed crystallization of free sulfisomidine. In the DSC curve (b), therefore, crystallization of free sulfisomidine must have occurred simultaneously in the temperature range of the first two endotherms.

Although all of the TG curves of the 1:2 adduct showed the same type of weight decrease in one step, a single set of simultaneous DSC and EGD curves (Fig. 6 (f) and (g)) suggested the possible existence of an intermediate adduct. The heat effect due to $\mathrm{NH}_{3}$ elimination was recorded as two independent DSC peaks in this case and the first one appeared at a temperature about $10^{\circ}$ lower than in usual cases. Thus, it is supposed that the $1: 2$ adduct can release $\mathrm{NH}_{3}$ by way of an intermediate, at least partly. It is likely, as with the aforementioned ad-

5) K. Sekiguchi, Y. Tsuda, and M. Kanke, Chem. Pharm. Bull., 23, 1353 (1975). 


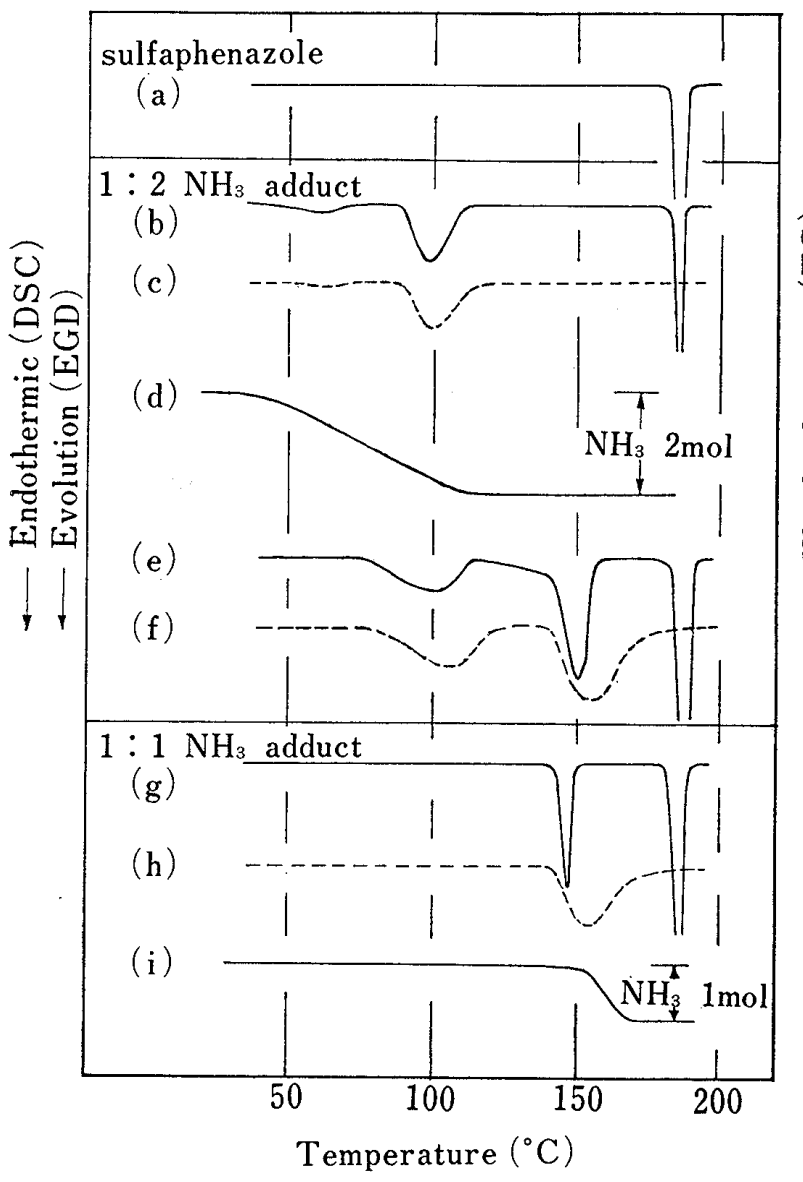

Fig. 5. DSC, EGD, and TG Curves of Sulfaphenazole and Its 1:2 and 1: $1 \mathrm{NH}_{3}$ Adducts

(a) DSC curve of sulfaphenazole under semi-closed conditions: sample weight, $8.72 \mathrm{mg}$; heating rate, $16^{\circ} / \mathrm{min}$.

(b) and (c) Simultaneous DSC and EGD curves of the 1:2 ad duct under semi-closed conditions: sample weight, $6.64 \mathrm{mg}$; heating rate, $16 \% \mathrm{~min}$.

(d) TG curve of the 1:2 adduct corresponding to the DSC curve (b) : sample weight, $4.506 \mathrm{mg}$; heating rate, $16^{\circ} / \mathrm{min}$

(e) and (f) Simultaneous DSC and EGD curves of the 1:2 adduct under semi-closed conditions: sample weight, $11.57 \mathrm{mg}$; heating rate, $16 \% \mathrm{~min}$.

$(\mathrm{g})$ and $(\mathrm{h})$ Simultaneous DSC and EGD curves of the $1: 1$ adduct under semi-closed conditions: sample weight, $5.46 \mathrm{mg}$; heating rate, $16^{\circ} / \mathrm{min}$.

(i) TG curve of the $1: 1$ adduct: sample weight, $5.870 \mathrm{mg}$; heating rate, $16 \% \mathrm{~min}$.

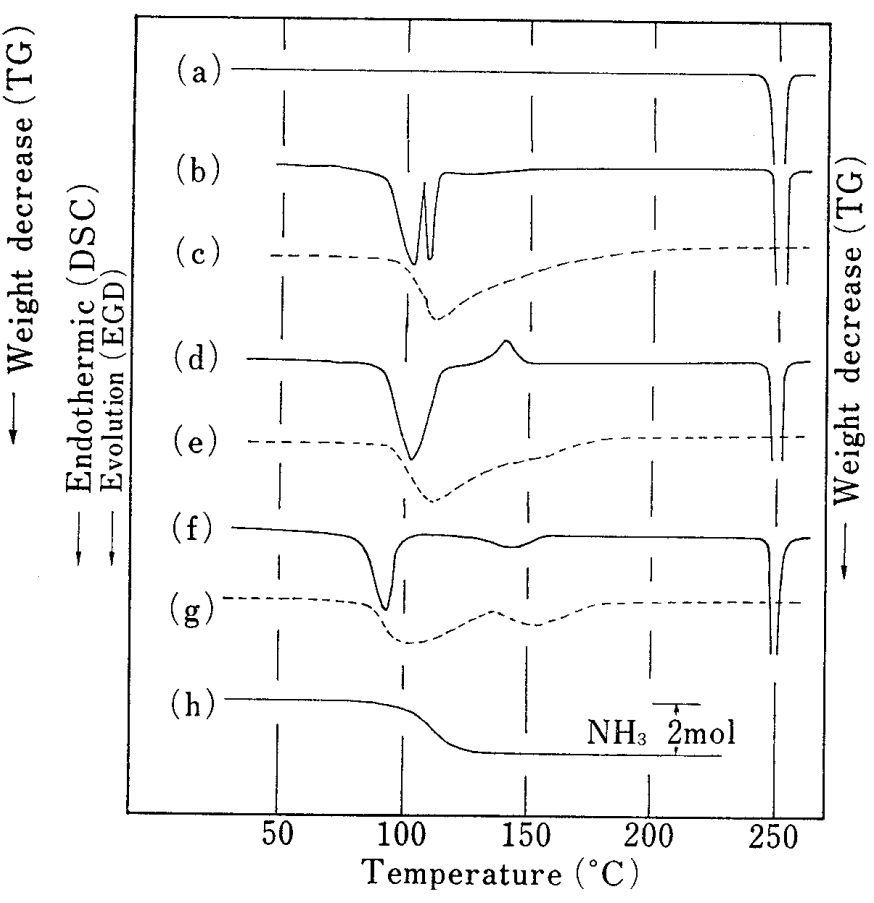

Fig. 6. DSC, EGD, and TG Curves of Sulfisomidine and Its 1:2 $\mathrm{NH}_{3}$ Adduct

(a) DSC curve of sulfisomidine under semi-closed conditions: sample weight, $4.26 \mathrm{mg}$; heating rate, $16^{\circ} / \mathrm{min}$.

(b) and (c) Simultaneous DSC and EGD curves of the 1:2 adduct under semi-closed conditions: sample weight, $4.83 \mathrm{mg}$; heating rate, $16^{\circ} / \mathrm{min}$.

(d) and (e) Simultaneous DSC and EGD curves of the 1:2 adduct under semi-closed conditions: sample weight, $12.79 \mathrm{mg}$; heating rate, $16^{\circ} / \mathrm{min}$.

(f) and ( $g$ ) Simultaneous DSC and EGD curves of the 1:2 adduct under semi-closed conditions: sample weight, $8.44 \mathrm{mg}$; heating rate, $16^{\circ} / \mathrm{min}$.

(h) TG curve of the 1:2 adduct: sample weight, $4.282 \mathrm{mg}$; heating rate, $16 \% \mathrm{~min}$.

ducts of other sulfonamides, that direct conversion to free sulfisomidine occurs metastably, but more easily in practice.

In the case of the 1:3 adduct, two sets of typical DSC and EGD curves were obtained under semi-closed conditions (Fig. 7 (a) (b) and (c) (d)). As depicted in curves (a) and (b), each endothermic DSC peak below $120^{\circ}$ corresponds to gas evolution in the EGD curve. Since the second and third DSC peaks are similar to those for the $1: 2$ adduct in Fig. 6 (b), it is supposed that the 1: 3 adduct was converted to sulfisomidine via the $1: 2$ adduct.

On the other hand, curves (c) and (d) in Fig. 7 are considered to indicate that the adduct was first melted completely and then converted directly to the free sulfonamide. This view is supported not only by the shape of the TG curve but also by the fact that the DSC curve (f) under closed conditions gave a single peak resembling the first endothermic peak under semiclosed conditions, and the residue after pan rupture was found to be a fused mass. Small 


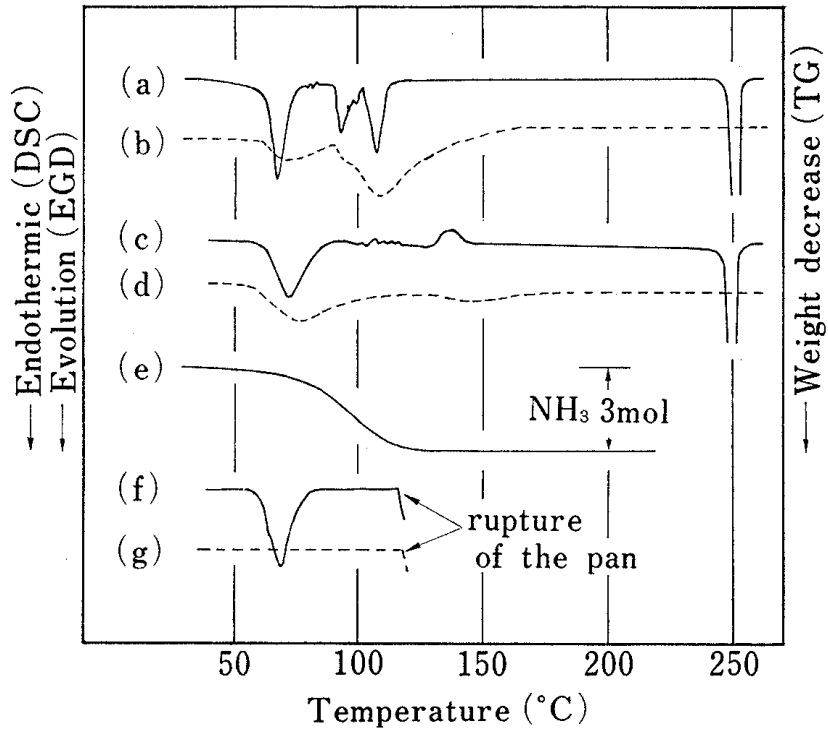

Fig. 7. DSC, EGD, and TG Curves of the $1: 3 \mathrm{NH}_{3}$ Adduct of Sulfisomidine

(a) and (b) Simultaneous DSC and EGD curves of the 1: adduct under semi-closed conditions: sample weight, $7.94 \mathrm{mg}$; heating rate, $16^{\circ} / \mathrm{min}$

(c) and (d) Simultaneous DSC and EGD curves of the 1: 3 adduct under semi-closed conditions: sample weight, $5.65 \mathrm{mg}$; heating rate, $16^{\circ} / \mathrm{min}$

(e) TG curve of the 1:3 adduct: sample weight, $5.467 \mathrm{mg}$; heating rate, $16^{\circ} / \mathrm{min}$.

(f) and (g) Simultaneous DSC and EGD curves of the 1: adduct under closed conditions: sample weight, $9.47 \mathrm{~m} \mathrm{~g}$; heating rate, $16^{\circ} / \mathrm{min}$.
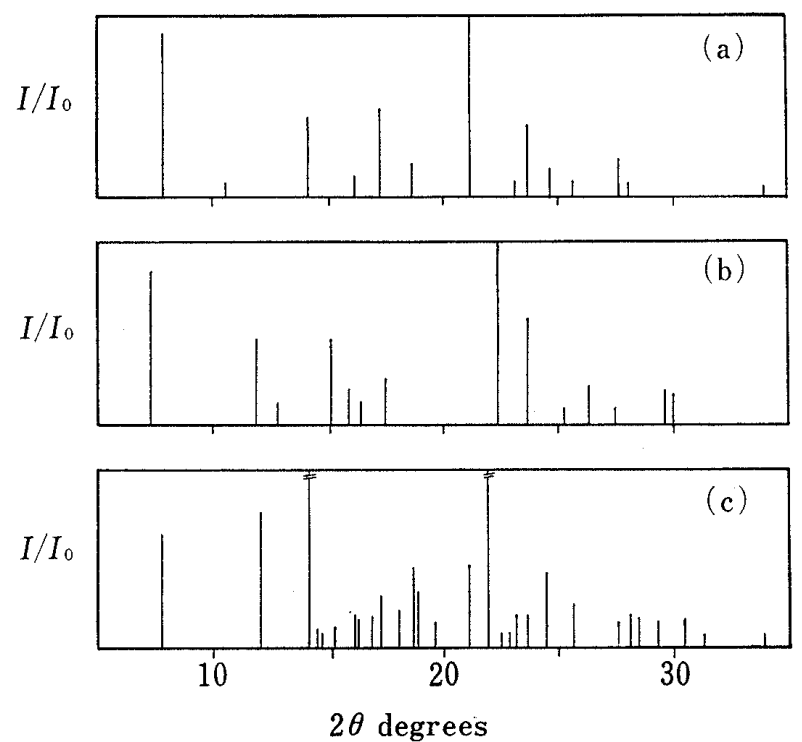

Fig. 9. X-Ray Diffraction Patterns of Sulfisomidine and Its $\mathrm{NH}_{3}$ Adducts

(a) Sulfisomidine, ccmmercial product.

(c) $1: 2$ Sulfisomidine $\mathrm{NH}_{3}$ adduct.

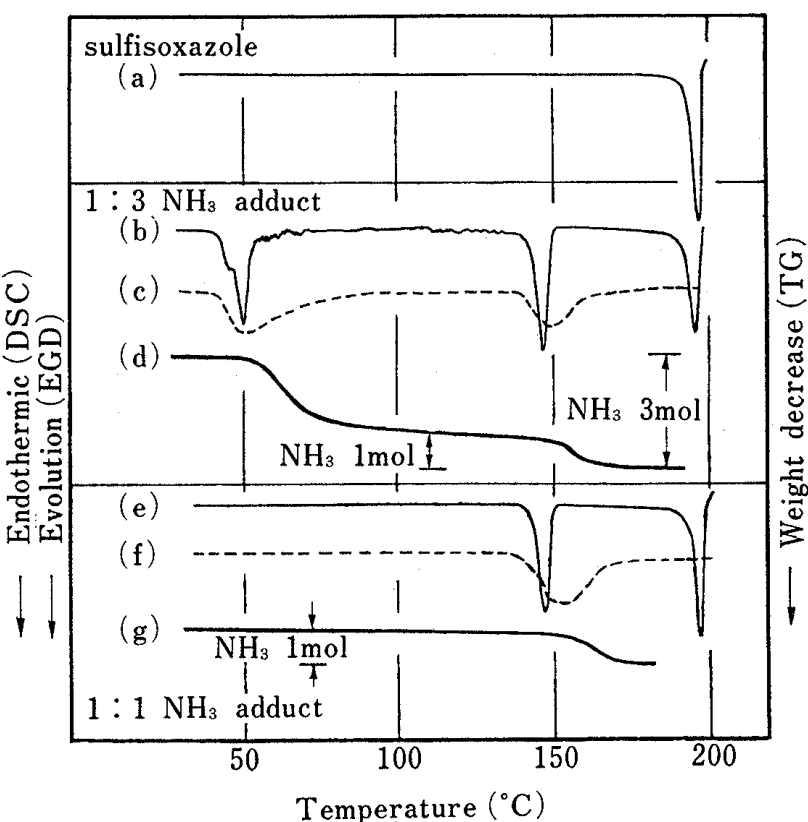

Fig. 8. DSC, EGD, and TG Curves of Sulfisoxazole and Its 1:3 and 1:1 $\mathrm{NH}_{3}$ Adducts

(a) DSC curve of sulfisoxazole under semi-closed conditions: sample weight, $6.68 \mathrm{mg}$; heating rate, $8^{\circ} / \mathrm{min}$.

(b) and (c) Simultaneous DSC and EGD curves of the $1: 3$ adduct under semi-closed conditions: sample weight, $5.46 \mathrm{mg}$; heating rate, $8^{\circ} / \mathrm{min}$.

(d) TG curve of the $1: 3$ adduct: sample weight, $3.745 \mathrm{mg}$; heating rate, $8 \% \mathrm{~min}$.

(e) and (f) Simultaneous DSC and EGD curves of the 1:1 adduct under semi-closed conditions: sample weight, $6.18 \mathrm{mg}$; heating rate, $8^{\circ} / \mathrm{min}$

(g) TG curve of the $1: 1$ adduct: sample weight, $4.023 \mathrm{mg}$; heating rate, $16^{\circ} / \mathrm{min}$.

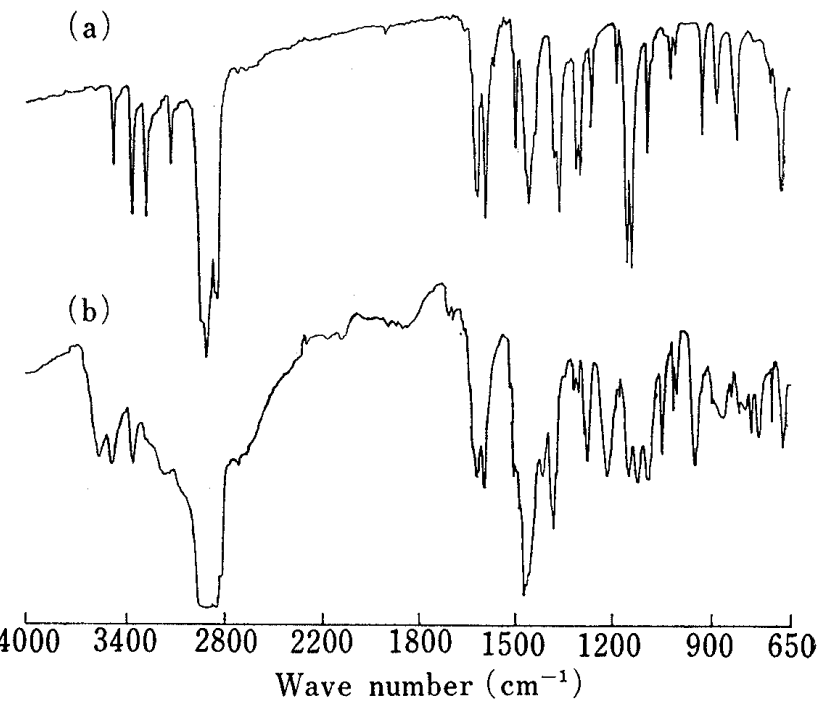

Fig. 10. Infrared Spectra of Sulfamethoxazole and Its $\mathrm{NH}_{3}$ Adduct (Nujol mulls)

(a) Sulfamethoxazole, commercial product.

(b) 1:2 Sulfamethoxazole $\mathrm{NH}_{3}$ adduct. 
fluctuations and the subsequent exothermic peak in curve (c) must be attributable to successive and concomitant occurrence of evaporation of $\mathrm{NH}_{3}$ and solidification of free sulfisomidine, respectively.

On comparing the DSC curves (a), (c), and (f) in Fig. 7, it is noticeable that each of the first endothermic peaks begins to appear at the same temperature of $60^{\circ}$. This result suggests that a phase reaction such as stable eutectic or peritectic fusion occurred in these cases. Therefore, it is likely that differences in the DSC patterns will depend on the mode of change in the sample composition, though the details are not clear.

6. $\mathbf{N H}_{3}$ Adducts of Sulfisoxazole — Two kinds of adducts were formed between sulfisoxazole and $\mathrm{NH}_{3}$. One was obtained by crystallization from an $\mathrm{NH}_{3}$ solution, while the other was obtained by allowing the crystals to stand at room temperature for a few days. As shown in the simultaneous DSC and EGD curves (b) (c) and (e) (f) in Fig. 8, it is evident that the former adduct is richer in $\mathrm{NH}_{3}$ and forms the latter as an intermediate during heating. From the TG curves (d) and (g), the combining ratios were determined to be $1: 3$ and $1: 1$ (sulfisoxazole: $\mathrm{NH}_{3}=1: 3.01$ and 1:0.98), respectively. Incidentally, as discussed in connection with the 1:2 adduct of sulfamethoxazole (Fig. 2 (e)), the fluctuations after the first endothermic peak in the DSC curve (b) should be caused by evaporation of $\mathrm{NH}_{3}$ and crystallization of the intermediate $1: 1$ adduct successively.

\section{$\mathrm{X}$-ray Diffractometry and IR of the $\mathbf{N H}_{3}$ Adducts}

The $\mathrm{NH}_{3}$ adducts of each sulfonamide were examined by X-ray diffractometry and IR. For example, as is evident from the $X$-ray patterns in Fig. 9, sulfisomidine and its $1: 3$ and $1: 2$ $\mathrm{NH}_{3}$ adducts are all different molecular species. However, the final products obtained by dissociation of $\mathrm{NH}_{3}$ showed the characteristic X-ray patterns of sulfisomidine itself.

Fig. 10 and 11 show the IR spectra of sulfamethoxazole, sulfisoxazole and their $\mathrm{NH}_{3}$ adducts measured by the nujol mull method. Almost all $\mathrm{NH}_{3}$ adducts of the sulfonamides

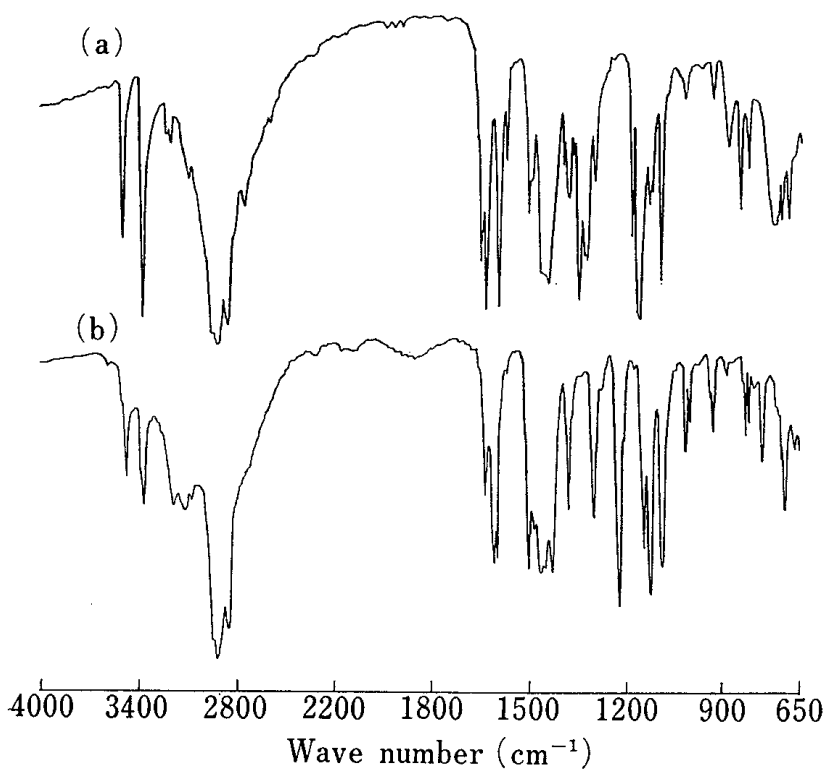

Fig. 11. Infrared Spectra of Sulfisoxazole and Its $\mathrm{NH}_{3}$ Adduct (Nujol mulls)

(a) Sulfisoxazole, commercial product.

(b) 1:1 Sulfisoxazole $\mathrm{NH}_{3}$ adduct. showed a strong band in the range of $1220-1230 \mathrm{~cm}^{-1}$, which may be assigned to the $\mathrm{NH}_{3}$ bending vibration. ${ }^{6}$ The symmetric and asymmetric $\mathrm{SO}_{2}$ stretching vibrational frequencies of the sulfonamides were seen in the ranges of $1140-1170 \mathrm{~cm}^{-1}$ and $1310-$ $1340 \mathrm{~cm}^{-1}$, respectively. On the other hand, these $\mathrm{SO}_{2}$ absorption bands for the corresponding $\mathrm{NH}_{3}$ adducts were shifted to lower frequencies. ${ }^{7}$ Therefore, one of the sites of $\mathrm{NH}_{3}$ association to the sulfonamides is considered to be the $-\mathrm{SO}_{2}$-group.

\section{Particle Size Reduction of Sulfonamides by $\mathrm{NH}_{3}$ Desorption}

The external appearances of crystals of the 1: 2 sulfisomidine adduct before and after $\mathrm{NH}_{3}$ desorption are shown in Fig. 12 (a) and (b), respectively. Relatively large aggregates were ob-

6) F.P. Reding and D.F. Hornig, J. Chem. Phys., 19, 594 (1951); R.D. Waldron and D.F. Hornig, J. Am. Chem. Soc., 75, 6079 (1953); R.J.H. Clark and C.S. Williams, J. Chem. Soc. $(A), 1966,1425$.

7) J.N. Baxter, J. Cymerman-Craig, and J.B. Willis, J. Chem. Soc., 1955, 669. 
tained after desorption of $\mathrm{NH}_{3}$ and were easily separated into the primary fine particles by light pulverization, as shown in Fig. 12 (c). The other sulfonamides recovered via $\mathrm{NH}_{3}$ adducts showed similar particle appearances. On the other hand, Fig. 12 (d) shows the particles of commercial sulfisomidine subjected to similar light pulverization.

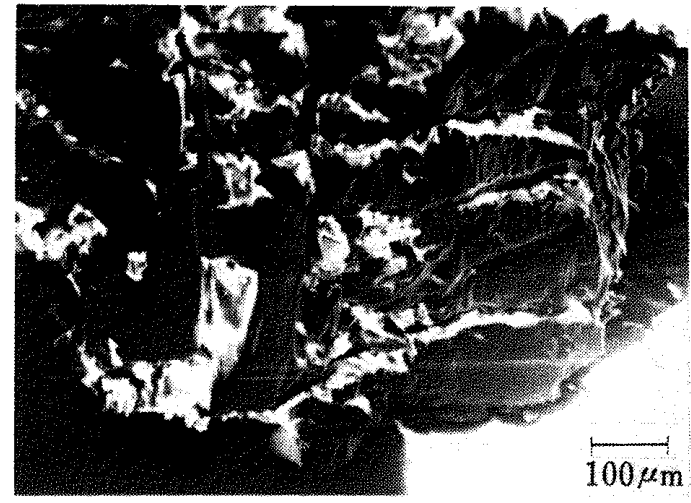

(a)

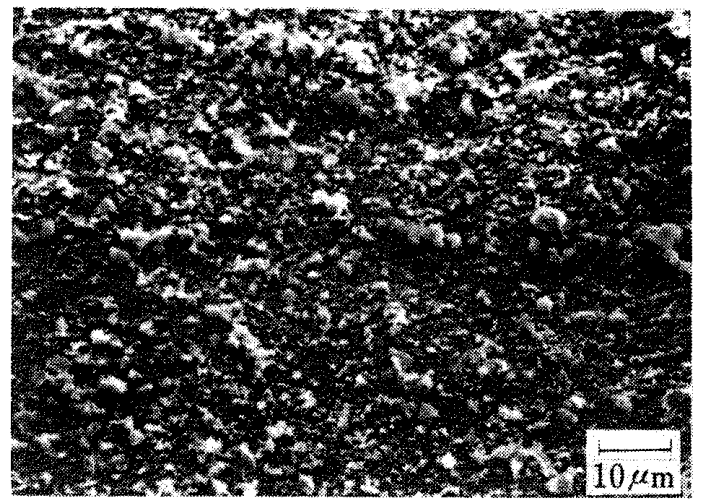

(c)

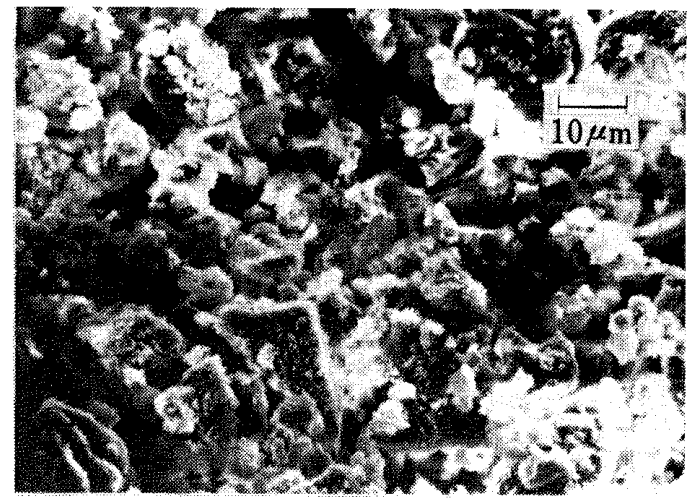

(b)

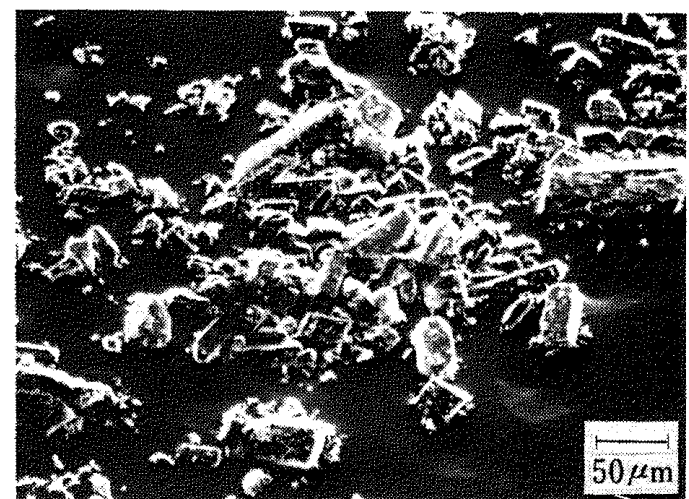

(d)

Fig. 12. Scanning Electron Micrographs of Sulfisomidine and Its 1:2 $\mathrm{NH}_{3}$ Adduct

(a) $\mathrm{NH}_{3}$ adduct crystal (before desorption).

(b) and (c) Sulfisomidine recovered from its $\mathrm{NH}_{3}$ adduct before and after pulverization, respectively.

(d) Commercial product pulverized.

Magnification: (a) $100 \times$, (b) $1000 \times$, (c) $1000 \times$, (d) $200 \times$.

TABle I. Results of Particle Size Reduction of Sulfonamides by $\mathrm{NH}_{3}$ Desorption from Their $\mathrm{NH}_{3}$ Adducts

\begin{tabular}{|c|c|c|c|c|}
\hline \multirow{2}{*}{$\mathrm{NH}_{3}$ adduct } & \multicolumn{2}{|c|}{$\mathrm{NH}_{3}$ desorption conditions } & \multicolumn{2}{|c|}{ Recovered sulfonamide } \\
\hline & Temperature and tin & me Pressure & $\begin{array}{l}\text { Specific } \\
\text { surface area }\end{array}$ & $\begin{array}{l}\text { Mean } \\
\text { diameter }\end{array}$ \\
\hline 1: 2 Sulfadimethoxine- $\mathrm{NH}_{3}$ & $\begin{array}{l}65^{\circ} \text { for } 2 \mathrm{hr} \text {, then } \\
105^{\circ} \text { for } 1.5 \mathrm{hr}\end{array}$ & $1-3 \mathrm{mmHg}$ & $2.4 \mathrm{~m}^{2} / \mathrm{g}$ & $1.9 \mu \mathrm{m}$ \\
\hline \multirow{3}{*}{$\begin{array}{l}\text { 1:2 Sulfamethoxazole- } \mathrm{NH}_{3} \\
1: 2 \text { Sulfanilamide- } \mathrm{NH}_{3} \\
1: 2 \text { Sulfaphenazole- } \mathrm{NH}_{3}\end{array}$} & $45^{\circ}$ for $3 \mathrm{hr}$ & $1-3 \mathrm{mmHg}$ & 4.4 & 1.0 \\
\hline & $-5^{\circ}$ for $2 \mathrm{hr}$ & Atmospheric & 2.0 & 2.1 \\
\hline & $\begin{array}{l}25^{\circ} \text { for } 3 \mathrm{hr} \text {, then } \\
100^{\circ} \text { for } 6 \mathrm{hr} \text {, then } \\
130^{\circ} \text { for } 1.5 \mathrm{hr}\end{array}$ & $1-3 \mathrm{mmHg}$ & 2.2 & 2.1 \\
\hline \multirow{3}{*}{$\begin{array}{l}\text { 1:3 Sulfisomidine- } \mathrm{NH}_{3} \\
\text { 1:2 Sulfisomidine-- } \mathrm{NH}_{3} \\
\text { 1: } 3 \text { Sulfisoxazole- } \mathrm{NH}_{3}\end{array}$} & $55^{\circ}$ for $9 \mathrm{hr}$ & $1-3 \mathrm{mmHg}$ & 3.3 & 1.4 \\
\hline & $65^{\circ}$ for $4 \mathrm{hr}$ & $1-3 \mathrm{mmHg}$ & 6.4 & 0.7 \\
\hline & $\left.\begin{array}{l}30^{\circ} \text { for } 5.5 \mathrm{hr} \text {, then } \\
130^{\circ} \text { for } 5.5 \mathrm{hr}\end{array}\right\}$ & $1-3 \mathrm{mmHg}$ & 1.7 & 2.7 \\
\hline
\end{tabular}


Conditions adopted for the desorption of $\mathrm{NH}_{3}$ and the specific surface areas of sulfonamide particles thus recovered are given in Table I. The mean particle diameter of each sulfonamide was also calculated on the assumption that the shape of particles is spherical. In every case, ultrafine particles were obtained by holding the sample below its decomposition temperature under reduced pressure and releasing $\mathrm{NH}_{3}$ without causing liquefaction before recovery of the sulfonamide.

\section{Conclusion}

It was found that at least 2 kinds of $\mathrm{NH}_{3}$ adducts were formed by 5 sulfonamides (sulfadimethoxine, sulfanilamide, sulfaphenazole, sulfisomidine, and sulfisoxazole), while one kind was formed by sulfamethoxazole. Ammonia evolution from the adducts would be expected to occur in a stepwise manner in the cases of sulfonamides which form 2 or more adducts; however, in many cases $\mathrm{NH}_{3}$-free sulfonamides were obtained directly without apparent formation of intermediate adducts during the process of deammoniation. It is thought that stable and/or metastable phase reactions may take place during thermal analysis. For effective particle size reduction, therefore, it is necessary to find suitable experimental conditions for $\mathrm{NH}_{3}$ elimination without liquefaction. 